University of Nebraska - Lincoln

DigitalCommons@University of Nebraska - Lincoln

\title{
TEM Study of FePt and FePt:C Composite Double-layered Thin Films
}

\author{
Xingzhong Li \\ University of Nebraska - Lincoln, xli2@unl.edu \\ T. George \\ University of Nebraska - Lincoln, tageorge@unlserve.unl.edu \\ Lingfang Jin \\ University of Nebraska - Lincoln
}

M. L. Yan

University of Nebraska-Lincoln, myan@unlserve.unl.edu

X. F. Xu

University of Nebraska - Lincoln

See next page for additional authors

Follow this and additional works at: https://digitalcommons.unl.edu/physicssellmyer

Part of the Physics Commons

Li, Xingzhong; George, T.; Jin, Lingfang; Yan, M. L.; Xu, X. F.; and Sellmyer, David J., "TEM Study of FePt and FePt:C Composite Double-layered Thin Films" (2007). David Sellmyer Publications. 217.

https://digitalcommons.unl.edu/physicssellmyer/217

This Article is brought to you for free and open access by the Research Papers in Physics and Astronomy at DigitalCommons@University of Nebraska - Lincoln. It has been accepted for inclusion in David Sellmyer Publications by an authorized administrator of DigitalCommons@University of Nebraska - Lincoln. 


\section{Authors}

Xingzhong Li, T. George, Lingfang Jin, M. L. Yan, X. F. Xu, and David J. Sellmyer 


\title{
TEM Study of FePt and FePt:C Composite Double-layered Thin Films
}

\author{
X.Z. Li, ${ }^{*}$ T. George, ${ }^{* *}$ Lingfang Jin, ${ }^{* *}$ M.L. Yan, ${ }^{*, * *}$ Y.F. Xu ${ }^{*, * *}$ and D.J. Sellmyer ${ }^{* * *}$ \\ *Nebraska Center for Materials and Nanoscience, University of Nebraska, Lincoln, NE 68588 \\ ${ }^{* *}$ Department of Physics and Astronomy, University of Nebraska, Lincoln, NE 68588
}

FePt films and FePt-based nano-composite films with the high-anisotropy $\mathrm{L}_{0}$ ordered phase have been extensively studied, since they have significant potential for extremely high-density perpendicular magnetic recording media and nano-composite permanent magnets [1]. Recently, new functional films were synthesized with a FePt:C composite layer on top of continuous FePt layer, in order to study the effect of the FePt layer on the ordering, orientation and magnetic properties of the composite layer. Transmission electron microscopy (TEM), together with X-ray diffraction, has been used to check the growth of the double-layered films and to study the microstructure, including the grain size, shape, orientation and distribution. The results have been used as feedback to improve the film synthesis and to analyze the structures related to novel functions of the designed films. In this report, the TEM studies of both single-layered nonepitaxially grown $\mathrm{FePt}$ and FePt:C composite $\mathrm{L}_{0}$ phase and double-layered deposition $\mathrm{FePt}: \mathrm{C} / \mathrm{FePt}$ are presented.

The (001) textured FePt L1 0 phase can be produced by nonepitaxial growth with controlled film thickness and a post-deposition annealing process [2]. The behavior of the (001) textured films has been systematically studied with a variety of the film thicknesses. X-ray diffraction experiments show a (001) preferred orientation can be obtained in thin films (less than $10 \mathrm{~nm}$ ), and random-like orientation develops as film thickness increasing and is dominant when film thickness is about 20 $\mathrm{nm}$. It seems that the degree of the (001) preferred texture smoothly decreases with the increase of the film thickness. Recently it is found that the (001) preferred texture changes from high to low, and then becomes high again as the thickness approaches $10 \mathrm{~nm}$. Electron diffraction (ED) experiments confirm formation of the (001) texture of the FePt L1 $1_{0}$ phase. Moreover, TEM images reveal that the FePt $\mathrm{L}_{0}$ phase does not cover the full surface of the substrate if the films are very thin. Fig. 1 (a) shows the morphology of the FePt L1 10 phase with a thickness of about $5 \mathrm{~nm}$ and (b) the selected-area electron diffraction (SAED) of the same film, indicating mainly nonepitaxial growth of the (001) texture and small amount of grains with random orientation. The change in the degree of the (001) preferred texture in thin films can be understood as the following film growth stages: (a) the film first develops a partial cover on the surface of substrate, (b) continued growth of the existent, (c) full coverage of the surface, and (d) increasing the thickness of the fully covered films. The first three stages correspond to the change of (001) preferred orientation degree within $10 \mathrm{~nm}$ and the last stage to the development and then dominance of the random orientated grains.

For perpendicular recording, the films of the $\mathrm{FePt} \mathrm{L} 1_{0}$ phase are required to have small grain size and uniform size distribution. The formation of composite films by embedding the FePt $\mathrm{L} 1_{0}$ phase in a carbon matrix is an effective way to control the grain size and distribution of the $\mathrm{FePt} \mathrm{L}_{0}$ phase $[3,4]$. It is found that the large $\mathrm{FePt} \mathrm{L1} 1_{0}$ grains are connected if the carbon layer is not thick enough, whereas the sparse $\mathrm{L}_{0} \mathrm{FePt}$ grains in carbon matrix if the carbon layer is too thick. Thus the thickness of the deposited carbon and FePt layers must be optimized in the films.

Nonepitaxially grown double-layered FePt:C/FePt thin films have been synthesized for the purpose 
of fine tuning magnetic properties. The results show that better magnetic properties for doublelayered FePt:C/FePt nano-composite can be achieved by decreasing the thickness of FePt layer. Fig. 2 shows the cross-sectional TEM image of the double-layered $\mathrm{FePt}$ :C/FePt nano-composite and (b) the electron diffraction pattern of the (001) texture of FePt:C composite, which was obtained from a plan-view specimen of the films, top layer of FePt:C composite. This work was supported by NSFMRSEC, INSIC, DOE and NCMN.

References

[1] D.J. Sellmyer, C.P. Liou, M.L. Yan and Y. Liu, IEEE Tran. Mag. 37 (2001) 1286.

[2] H. Zeng, M.L. Yan, N. Power, and D.J. Sellmyer, Appl. Phys. Lett. 80 (2002) 2350.

[3] Y. Zhang, J. Wan, M.J. Bonder, and G.C. Hadjipanayis, J. Appl. Phys. 93 (2003) 7175.

[4] M.L. Yan, R.F. Sabirianov, Y.F. Xu, X.Z. Li and D.J. Sellmyer, IEEE. Tran. Mag. 40 (2004) 2470 .

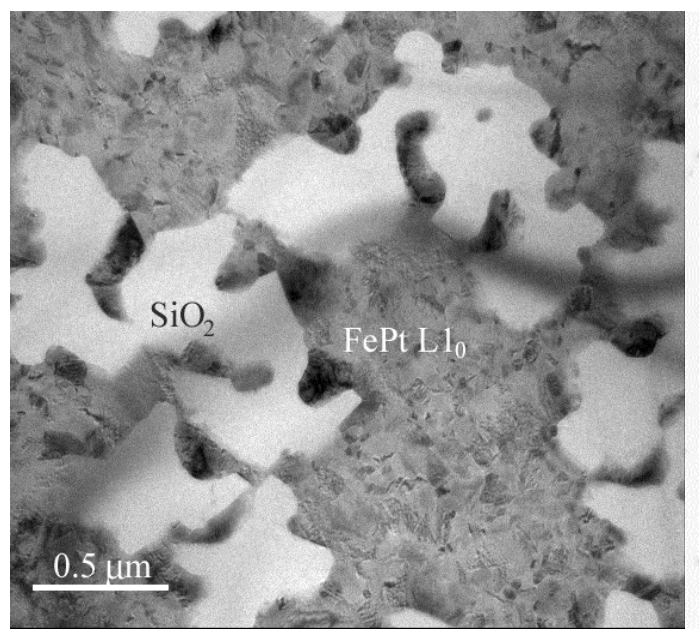

(a)

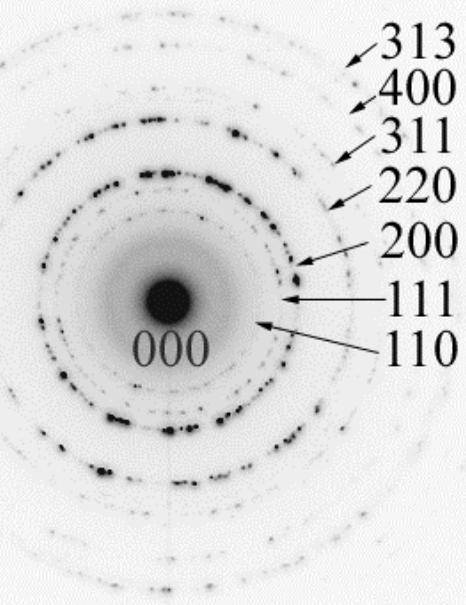

(b)

Fig.1 (a) an FePt L1 $1_{0}$ ultra-thin film and (b) a SAED pattern of the (001) preferred orientation.

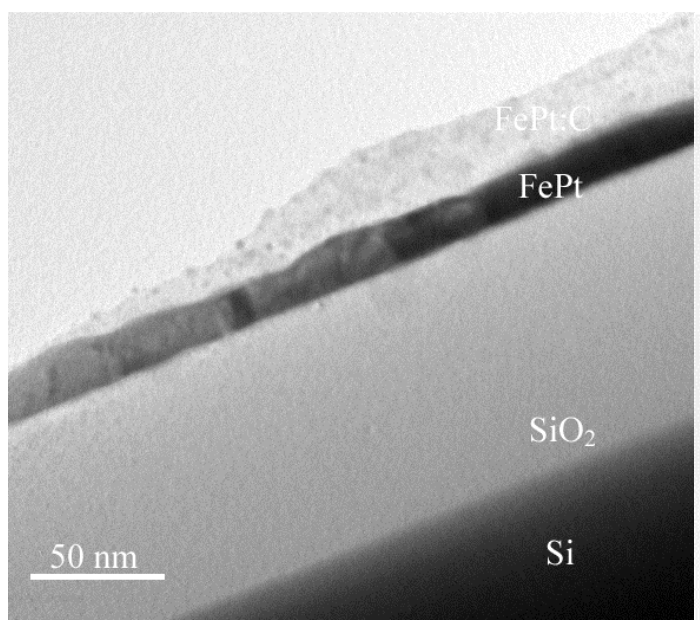

(a)

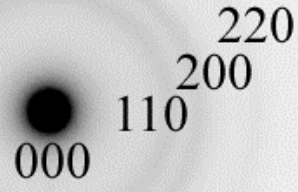

(b)

Fig. 2 (a) an FePt and FePt:C double-layered functional thin film and (b) a SAED pattern of the $\mathrm{FePt} / \mathrm{C}$ top-layer with incident electron beam perpendicular to film surface. 